IRA-International Journal of Management \& Social Sciences

ISSN 2455-2267; Vol.04, Issue 01 (2016)

Institute of Research Advances

http://research-advances.org/index.php/RAJMSS

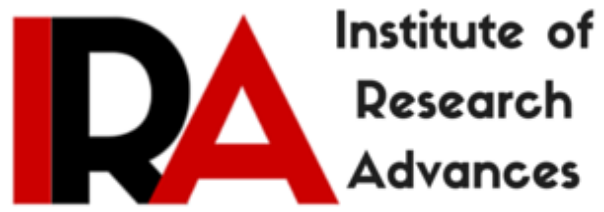

\title{
Tapping the Untapped: Huge Potential to Increase Family Planning Users in India
}

\author{
${ }^{1}$ Lopamudra Paul, \\ The UNION, New Delhi, India. \\ ${ }^{2}$ Subrato K Mondal \\ Oxford Policy Management Ltd.; New Delhi, India. \\ ${ }^{3}$ Geeta Nanda \\ FHI 360, USA. \\ ${ }^{4}$ Kara E. Tureski \\ FHI 360, USA. \\ ${ }^{5}$ Ajay K Singh \\ MAMTA Health Institute for Mother and Child, New Delhi, India. \\ ${ }^{6}$ Tara Sharma \\ Population Services International; New Delhi, India.
}

DOI: http://dx.doi.org/10.21013/jmss.v4.n1.p5

\section{How to cite this paper:}

Paul, L., Mondal, S., Nanda, G., Tureski, K., Singh, A., \& Sharma, T. (2016). Tapping the Untapped: Huge Potential to Increase Family Planning Users in India. IRAInternational Journal of Management \& Social Sciences (ISSN 2455-2267), 4(1). doi:http://dx.doi.org/10.21013/jmss.v4.n1.p5

(C) Institute of Research Advances

\section{(cc) BY-NO}

This works is licensed under a Creative Commons Attribution-Non Commercial 4.0 International License subject to proper citation to the publication source of the work.

Disclaimer: The scholarly papers as reviewed and published by the Institute of Research Advances (IRA) are the views and opinions of their respective authors and are not the views or opinions of the IRA. The IRA disclaims of any harm or loss caused due to the published content to any party. 


\begin{abstract}
India's family planning programs have historically focused on limiting the number of children but in recent years focus has shifted from limiting births to increased spacing between children, especially among young couples on contraceptive acceptance in the post-partum period. This paper examines the behavior of couples in India on acceptance of contraceptives during the postpartum period by using data from the National Family Health Survey-3 (NFHS-3, 2005-06) and from a small scale survey in state of Chhattisgarh in India.

According to the data, approximately 75 percent of women with children under a year and 83 percent of women with children under six months' old reported not using any contraception. Only 0.9 percent of postpartum women reported acceptance of intrauterine contraceptive devices. The primary reasons cited for not using contraception were breast feeding $(27.5$ percent $)$ and postpartum amenorrhea (16.9 percent). Education and wealth index and program factor specially interaction with health workers during post-partum period and institutional delivery had a significant effect on acceptance of contraceptives during the postpartum period. Achieving one's desired family size also positively influenced women's acceptance of family size soon after delivery. Small scale survey in Chhattisgarh also suggested that acceptance of family planning to space children is not high.
\end{abstract}

\title{
1. BACKGROUND
}

Use of contraceptives is low among women in India. According to NFHS-3, only 55.8 percent of currently married women were using any modern contraceptives and two third among those women who are currently using modern contraceptives are using permanent method i.e., female sterilization (IIPS, 2007). The focus of the Family Planning (FP) Program in India, historically, has been on limiting the number of children rather than promoting birth spacing. However, in recent years, the Government of India's efforts to reposition FP shifted this focus from limiting births to spacing between children, especially among young couples.

According to NFHS-3 data, the majority of married women (90 percent) during postpartum (within their first year after child birth) reported that they wanted to delay their next pregnancy by at least two years (Ross and Winfrey, 2001). A desire for using FP to space their next pregnancy was also higher among postpartum women as compared with other married women of reproductive age (Borda and Winfrey, 2010). Solanki et al. (2013) conducted a comparative study among 363 married women of reproductive age in rural Maharashtra in India on met and unmet need for contraception (based on contraceptive use) and showed that the prevalence of contraceptive use among those with a met need was 59.2 percent as compared with only 44.2 percent for those with unmet need. A study of 123 women who had delivered their last child within a year was conducted to examine postpartum contraceptive use in rural Bareilly in Uttar Pradesh, India (Mahmood et al., 2011). Results showed that only 13.8 percent of women had adopted postpartum contraception. Lack of knowledge and breastfeeding were cited as the main reasons for not accepting contraceptives. Educational level was found to be a significant influence of a woman's contraceptive use.

According to Faculty of Family Planning and Reproductive Health report, breastfeeding was one of the major reasons cited for not using contraceptives during the postpartum period, as women were advised that if they were less than six months postpartum, amenorrhoeic, and exclusively breastfeeding, then their risk of pregnancy was reduced to only two percent. But most of women were not aware that the absence of any of these conditions, especially cessation of night feeding, increased their risk of pregnancy by several times (FFPRHC, 2004). Ekpenyoung et al. (2013) assessed the lactational amenorrhea method (LAM) as a method of postpartum contraception among women ages 18-40 years in Nigeria and found that the incidence of unintended pregnancy was 14.3 percent among LAM users. These women were only using LAM during the postpartum period before the onset of pregnancy. Another study of 272 mothers in Lucknow, India who delivered their babies within an institution looked at the pattern of breastfeeding as it related to return to fertility. Their study showed 
that 28 percent of women were sexually active within six weeks after child birth and 64.5 percent returned to fertility within six months. Most of these women used a condom for contraception (54.4 percent). The study showed that exclusive breastfeeding was poor in India and timely introduction of contraception and institutional delivery needed to be encouraged (Kunwar et al., 2010). Another study by Kishor, et al. (2010) among 42 families in the rural village of Wardha in India showed that most mothers delivered again when their youngest child was less than two years old.

Acceptance of contraceptives is higher among couples who have already completed their desired family size (NFHS-3, 2006). However, in India, with low acceptance of family planning methods in total and higher dependence on permanent method may force women to accept female sterilization at very young age after they had completed their desired family size. A study conducted in Andhra Pradesh in India revealed that most women accepted female sterilization along with or just after child birth in India (Padmadas, Hutter and Willekens, 2004).

Postpartum contraceptive such as IUCD insertion within 48 hours of delivery may help women to restrict unintended pregnancy during post- partum period. A hospital based study among 1317 women Lucknow, Uttar Pradesh revealed that providing highly effective contraception immediately after delivery provide advantages to avoid unintended pregnancy particularly where women have limited access to health facility (Shukla et al., 2012).

\section{GOAL AND OBJECTIVES}

The overarching goal of this paper was to understand underlying factors associated with increased acceptance of postpartum FP to improve maternal and child health outcomes. This paper tried to understand the attitudes and behavior of currently married couples related to acceptance of contraceptives during the postpartum period. Specific objectives were:

- To estimate contraceptive acceptance among couples during the postpartum period

- To examine the type of contraceptives used by couples who had a child less than one year.

- To understand the socio-economic and demographic factors associated with acceptance of contraceptives during postpartum period.

- To examine how feelings of having completed one's desired family size and breast feeding affect contraceptive acceptance during the postpartum period.

- To estimate intention to use postpartum IUCD (PPIUCD) in one state in India, viz., Chhattisgarh.

\section{METHODOLOGY}

This paper used data from the National Family Health Survey-3 (NFHS-3, 2005-06) in India and also a small scale study conducted by IHBP in Chhattisgarh, a state in India Data was analysed to measure first four objectives from the NFHS-3 data whereas for the last objective data was used from a small scale survey conducted in Chhattisgarh by IHBP. During NFHS-3 information collected on fertility, family building process i.e, marriage, conception, delivery etc., use of contraception, and also other background characteristics from ever-married women. Though NFHS-3 collected data among 124, 385 women aged 15-49 years, 74369 men aged 15-54 years from 109,041 households in India but the current paper, only explored data collected from currently married women who had a child less than one year old during the time of the survey. Accordingly, there were 10,755 currently married women were found from the above sample of 124,385 women who reside in India and who had a child less than one years of age during the NFHS-3 survey as the sample for the current study. In addition to that, among these 10755 women, 5,296 had a child less than six months of age.

The Improving Healthy Behaviors Program (IHBP) in India, a United States Agency for International Development (USAID)-funded program managed by FHI 360 conducted a study in Chhattisgarh, India to capture the reach and recall of a FP campaign developed by IHBP and implemented by the National Rural Health Mission (NRHM), Government of Chhattisgarh. The study design included a cross-sectional household survey and a multi-stage cluster sampling approach to reach the desired number of target respondents. Two districts were selected randomly out of each of 
the three administrative regions of the state. The six districts that were selected in the state were Jashpur and Surguja (region 1), Durg and Raipur (region 2), and Bastar and Kanker (region 3). In each of the selected districts, primary sampling units (PSUs) were selected through the probability proportional to size (PPS) approach. This approach enabled all the small and large PSUs an equal probability of being selected into the final sample. A total of 86 PSUs were selected, including 66 rural and 20 urban locations. From the selected PSUs, an equal number of PSUs for males and females were selected randomly.

Figure 1 : Map of Chhattisgarh state and study districts

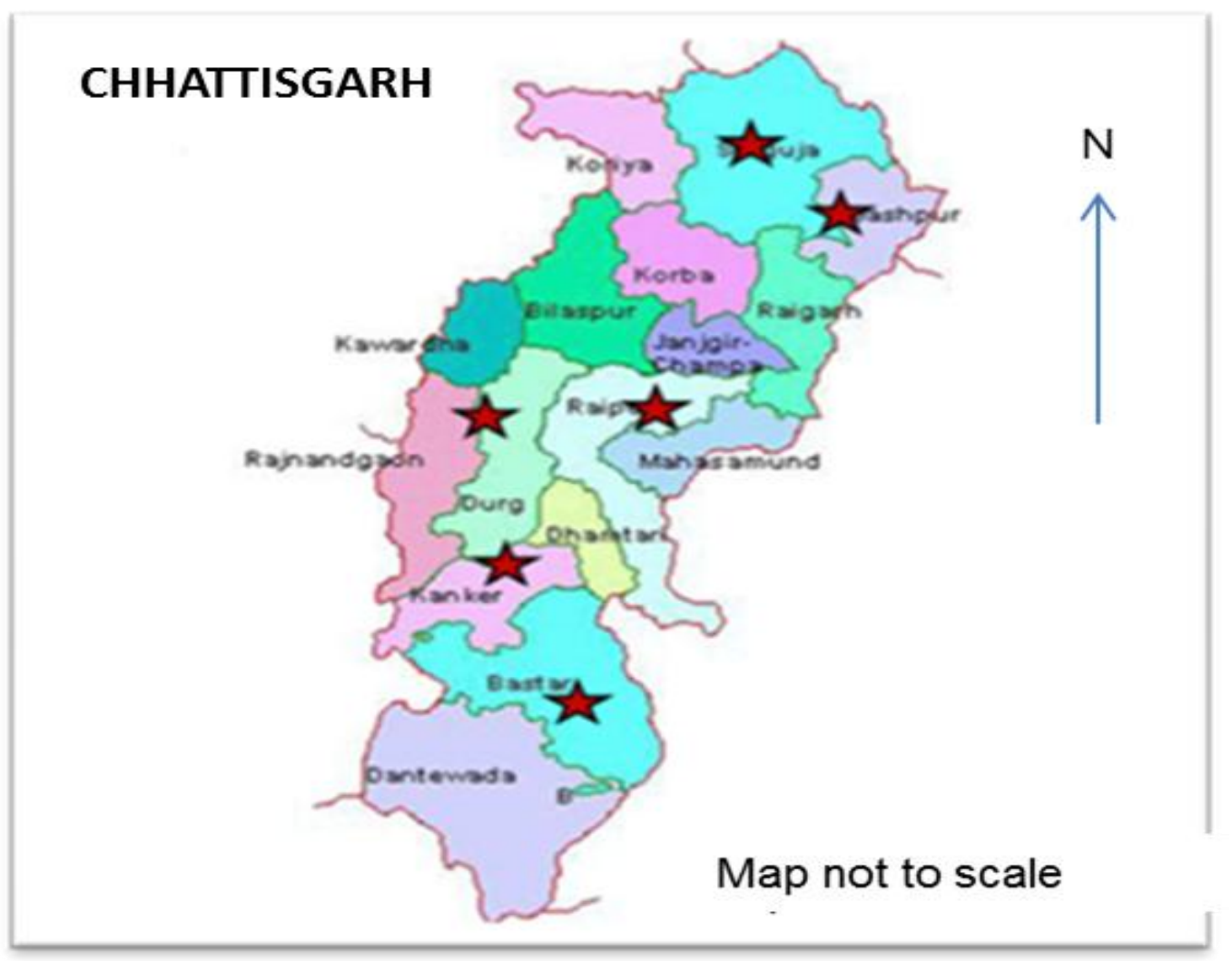

To generate the sampling frame for respondent selection, within each selected PSU, a household listing exercise was initially conducted in which key information on households was collected (i.e., name, age, number of children, availability status within next 10 days, etc.). Married men (18-34 years) and women (18-29 years) who were currently married, had at least one living child, and were not using any permanent method by him/herself and by his/her spouse were selected from different households using systematic random sampling to achieve the target sample in each PSU. Within each selected household, only one interview was conducted, either with a male or female respondent who provided consent depending on the PSU (i.e., whether it was a male- or female-specified PSU). As such, there was no possibility of any overlap of women or men with their respective spouses. In case there was more than one eligible respondent in a household, only one of them was selected using a "Kish Grid" (Kish, 1949).

Though the primary objective of this survey in Chhattisgarh was to estimate reach and recall of the FP campaign developed by IHBP, FHI 360, data on knowledge and acceptance of FP methods were also collected in addition to motivation to use FP methods in the future. A total of 1,655 respondents were interviewed face-to-face, using a structured questionnaire in Hindi during the study period from September-October 2013, including 827 male and 828 female respondents. The study was approved by FHI 360's Institutional Review Board (IRB) as well as by a recognized local IRB in 
India. Informed consent (verbal) was obtained from all study respondents who agreed to participate in the study.

This paper uses data collected on awareness and practice of FP methods among male and female in the survey in Chhattisgarh. The NFHS-3 survey was conducted during 2005-06. Government of India (GOI) has introduced schemes like Janani Surakshya Yojana (JSY) and Janani Sishu Surakshya Karyakram (JSSK) under NRHM in 2005 which are mostly encouraging women to deliver at health facility. Recent survey by IHBP in Chhattisgarh is complementing the NFHS-3 study finding by measuring data collected more recent on contraceptive use and intention to use contraceptive among women (18-29 years) and men (18-34 years).

Several studies show that acceptance of contraceptives is influenced by several socio-economic factors such as place of residence, religion, caste, educational level of women, wealth index of the household, parity, and also influence by health/community workers (Gangopadhyay and Das, 1997; Aremu, 2013; Solanki et al., 2013). It is also assumed that institutional delivery may influence acceptance of contraceptives during the postpartum period to limit the family size or space the next birth (Banerjee, 2004; Mahmood et al., 2011; Choudhari et al., 2013; Sedgh et al., 2014;). Breastfeeding has also been shown to play a significant role in delaying the acceptance of contraceptives during this period (Mosley et al., 1977; Laukaran and Labbok, 1993; Millman, 1993; Kennedy et al., 1993; Kishor et al., 2010; Kunwar et al., 2010; Ekpenyong et al., 2013; Manjunath et al, 2014). To estimate the potential effect of each factor on acceptance of contraceptives during the postpartum period, a bi-variate analysis was first conducted from NFHS-3 data. Second, the associations were also assessed in a multivariate analysis using a logistic regression model from large scale data collected during NFHS-3. Intension to use contraceptives after child birth was also estimated from the primary survey at Chhattisgarh among women (18-29 years old) and men (18-34 years).

\section{FINDINGS:}

\subsection{Evidence from large scale survey (NFHS-3)}

According to estimates from NFHS-3, almost 75 percent of young women who had a child less than one year old reported not currently using any contraceptive methods (Table 1). Further, 83 percent women who had a child less than six months of age also reported not using any contraceptive methods to prevent pregnancy. This shows that the majority of women were not adopting any contraceptive methods either modern or traditional to prevent further pregnancy during the postpartum period. Only 25 percent of women used any type of contraception to prevent pregnancy. Among modern contraceptive users (20.1 percent) who had a child less than one year, the most frequently adopted permanent method was female sterilization (10.3 percent). This demonstrated that the use of contraceptives during the postpartum period was very low and mostly associated with limits to family size and not for the purposed of spacing children. Acceptance of IUCD, which is currently promoted by the Government of India (GOI) for spacing between births was very low among postpartum women (0.9 percent). Moreover, a substantial proportion of couples used traditional methods, such as periodic abstinence (3.3 percent) and withdrawal (2.0 percent) during the postpartum period.

Table 1: Percentage of currently married women using contraceptives during the survey (NFHS-3), 2005-06

Type of contraceptive use Women with child less than Women with a child aged less

one year than 6 months

\section{No methods}

Any method

\section{5}

25.5

82.9

17.1 
Any modern method

Traditional method
20.1

13.8

5.4

Types of modern contraceptive methods used

\begin{tabular}{lcc}
\hline Pill* & 2.2 & 1.2 \\
IUCD* & 0.9 & 0.3 \\
Injectables* & 0.1 & 0.1 \\
Condom* & 6.5 & 4.9 \\
Female sterilization & 10.3 & 7.2 \\
Male sterilization & 0.1 & 0.1 \\
Periodic abstinence & 3.3 & 1.9 \\
Withdrawal & 2.0 & 1.3 \\
Folkloric method & 0.1 & 0.1 \\
\hline Total no. of women & $\mathbf{1 0 , 7 5 5}$ & $\mathbf{5 , 2 9 6}$ \\
\hline
\end{tabular}

Source: Computed from NFHS-3 data files

Traditional methods increase the risk for unwanted pregnancy during the postpartum period and may negatively affect maternal and child health. While looking at the Table-1, it is clear that among modern temporary methods used, use of condom was the highest among all other available temporary methods to delay or limit pregnancy.

Table 2: Reasons cited for not using contraceptive methods by women (NFHS-3), 2005-06

\begin{tabular}{lcc}
\hline Reasons for not using & Women who had a child less & Women who had a child less \\
contraceptive methods & than 12 months old & than six months old \\
& (in percent) & (in percent) \\
\hline
\end{tabular}

\begin{tabular}{lcc}
\hline Not having sex & 4.4 & 5.7 \\
Infrequent sex & 5.2 & 5.3 \\
Postpartum amenorrhea & 16.9 & 22.7 \\
Breast feeding & 27.5 & 36.4 \\
Husband opposed & 5.8 & 5.5 \\
Cost too much & 1.5 & 1.3 \\
Health concern & 3.2 & 2.6 \\
Fear of side effects & 3.5 & 3.2 \\
\hline Total No. of women & $\mathbf{1 0 , 7 5 5}$ & $\mathbf{5 , 2 9 6}$ \\
\hline
\end{tabular}

Source: Computed from NFHS-3 data files 
As estimated from NFHS-3, the majority of women who had a child less than a year old reported not using any contraceptives at the time of survey (Table 2). The main reasons cited for not using contraceptives were breast feeding (27.5 percent) and reported postpartum amenorrhea (16.9 percent). The literature showed that women believed that breastfeeding reduced risk of pregnancy during the postpartum period. However, exclusive breast feeding and breast feeding, in general, do not have the same protective effects against pregnancy. Often, women considered the protective effects of any breast feeding toward pregnancy to be the same as exclusive breast feeding (Mosley et al, 1977; Kishor et al, 2010; Kunwar et al, 2010). This may be high among women who had a child less than six months. Postpartum amenorrhea is also closely associated with exclusive breast feeding and hence women who had a child less than six months of age frequently reported this as a reason for not using contraceptives.

A few respondents also reported their husband's opposition (5.8 percent), infrequent sex (5.2 percent), and not having sex (4.4 percent) as reasons for not using contraception in the postpartum period. Learning from India program of ACCESS funded by USAID shows that women were at risk for pregnancy even though they are having infrequent sex without any contraceptive used during intercourse and when husband opposed for using condom, as there is a probability of return to fertility within a month of child birth ${ }^{1}$ Among respondents who had reported currently breastfeeding their child; only 9.4 percent were currently using modern contraceptives to delay their next child. Similarly, women who had reported being amenorrhoric during the survey were rarely using ( 3.7 percent) any modern contraceptives.

Acceptance of contraceptives, especially methods to limit family size is common in India (NFHS-3). According to NFHS-3 estimates, total demand for FP was 54.5 percent among currently married women aged 20-24 and 72.4 percent among women 25-29 years old. However, the majority of women reported that their need for FP was for limiting births, 27.8 percent and 59.6 percent of women aged 20-24 and 25-29 years respectively. Results from NFHS-3 data showed that one fourth of women in the postpartum period who accepted contraceptives, had met a health/community health worker (CHW) auxiliary nurse and midwife (ANM)/anaganwadi worker (AWW)/lady health visitor (LHV) in the past three months (Table 3). The majority of women reported that during their meetings, the health worker discussed on immunization or other childhood diseases and postnatal care, etc. FP was not given importance and only 4.3 percent women reported that health workers discussed FP during their meeting in past three months. FP is an important issue to discuss during the post natal period with women during $\mathrm{RCH}$ program implemented by Government of India however health workers showed lower interest on discussing Family during their visit/meeting with women during post partum period. RCH-II program was intended to integrated family planning with child health and hence focus was to counsel women during post partum visit and also during immunization of the child.

Table 3: Interaction with health/community workers in past three months (among women who had a child less than a year old), (NFHS-3), 2005-06

\begin{tabular}{lc}
\hline $\begin{array}{l}\text { Percentage of women who reported meeting an } \\
\text { ANM/LHV/AWW/CHW in the past three months }\end{array}$ & $\mathbf{4 3 . 5}$ \\
\hline \multicolumn{1}{c}{ Among who had meet health/community worker had discussed following topics } \\
& \\
(multiple answers) & $\mathbf{4 . 3}$ \\
Family Planning & $\mathbf{3 4 . 3}$ \\
Immunization & 4.3 \\
Supplementary food & 3.3 \\
Growth monitoring & 19.3 \\
Others (postnatal care, early childhood care, disease & \\
prevention etc.) &
\end{tabular}

Source: Computed from NFHS-3 data.

${ }^{1}$ Available at http://www.accesstohealth.org/toolres/pubs.htm. 
Table 4 presents the association analysis based on odds ratios (OR) of socio-economic and program factors as they may influence women's acceptance of contraceptives during the postpartum period (Table 4). Acceptance of contraceptives was higher among women living in urban areas (35.9 percent) as compared with rural areas (22.1 percent). There was marginal difference in acceptance of contraceptives during one year after child birth across religious groups. Among all ethnic groups, women who belonged to the scheduled caste community reported the lowest acceptance of contraceptive methods (19.4 percent) whereas 30.2 percent women from higher castes (non-scheduled Caste/Scheduled Tribes/Other Backward Castes) reported acceptance of contraceptives within one year of child birth. Apart from young women (15-19 years), there was marginal difference found looking at age and use of contraceptives among those who had a child less than one year old. The data also showed that increases in educational level and also increase in wealth index also increases acceptance of contraceptives among women who had a child less than one year of age. Women who had an institutional delivery also reported higher acceptance of FP methods (34.0 percent) than those who delivered outside of an institution (14.4 percent). However, less than one third of respondents who had completed their desired family size reported (30.1 percent) that they were currently using contraceptives. The data did not differ much among those who had not completed their desired family size. Breastfeeding and interaction with health workers had marginal difference on acceptance of contraceptives among women with children less than a year.

A multivariate analysis was done to see how socio-economic and demographic factors affected the acceptance of contraceptives during the postpartum period (Annex Table 4). This also helped to understand the effect of program factors (like interaction/met with health care/community level health workers or having institutional delivery) after controlling for socio-economic and demographic factors. Results revealed that education and wealth index had a significant effect on the acceptance of contraceptives during the postpartum period in addition to program factors and institutional delivery among women with children less than one year. Women who had delivered within an institution were significantly more likely to accept contraceptives during this period as well as those women who had achieved their desired family size. Urban women were more likely to accept contraceptives during the postpartum period than their rural counterparts but the effect of place of residence was not significant on contraceptive acceptance after controlling for other factors. Religion and ethnicity did not vary as much as related to acceptance of contraceptives. Women who had met a health worker during the past three months or had an institutional delivery were significantly more likely to accept contraceptives during this period. This clearly showed a program effect through generating awareness and motivation through inter personal communication. Achieving one's desired family size also positively influenced women's acceptance of FP during post-partum period. Though breastfeeding was considered another major reason why women delay accepting contraceptives, the association of breastfeeding and contraceptive use was not significant.

It was found in the multivariate analysis that likelihood of accepting contraceptives within one year of child birth was significantly higher among women who had completed their desired family size as compared with those who had not or who were still undecided. When the data was disaggregated by type of contraceptive accepted (Table 5), it was found that majority of women had already accepted a permanent family planning method (23.4 percent) among family planning acceptors, however, almost 70 percent women are not using any kind of family planning methods even they reported to having desired number of living children during the survey. Use of modern temporary contraceptive methods were also lowest among who had already reported to be completed their desired family size. 
Table 5: Percentage of women using contraceptives by desired family size

\section{Desired family size}

Use of contraceptives

\begin{tabular}{ccc}
\hline $\begin{array}{c}\text { Permanent method } \\
\text { (female sterilization \& } \\
\text { male sterilization) }\end{array}$ & $\begin{array}{c}\text { Modern } \\
\text { temporary } \\
\text { methods }\end{array}$ & No method \\
\hline 7.0 & 6.5 & \\
\hline
\end{tabular}

Undecided

7.0

6.5

86.5

Have number of living

23.4

6.7

69.9

children as desired or more

Have number of living child

lower than desired

Source: Computed from NFHS-3 data

\subsection{Evidence from small scale survey in Chhattisgarh, India}

The primary survey in Chhattisgarh showed that the majority of respondents were knowledgeable about the optimal spacing of three years between children as promoted by the GOI and in the IHBP-developed FP campaign (41.6 percent) though this knowledge was proportionally higher among urban respondents than rural. Though a very low percentage of women perceived that one year as ideal gap between two children but almost one third of women have reported two years as ideal gap between children.

Table 6: Percentage of men and women having knowledge of optimal gap between children (N1,655)

\begin{tabular}{lccc}
\hline Gap between children (in years) & \multicolumn{3}{c}{ Place of residence } \\
\cline { 2 - 4 } & Rural & Urban & Total \\
\hline One & 4.1 & 1.2 & 3.4 \\
Two & 37.7 & 21.3 & 29.1 \\
Three (ideal and promoted) & $\mathbf{3 6 . 1}$ & $\mathbf{5 8 . 7}$ & $\mathbf{4 1 . 6}$ \\
Above three & 5.0 & 11.0 & 6.5 \\
Don't not know & 23.2 & 7.8 & 19.4 \\
\hline
\end{tabular}

Source: IHBP survey, Chhattisgarh; 2013

Discussion on FP is considered an important factor in spousal communication as it relates to contraceptive uptake. The data revealed that 27.5 percent of respondents had discussed FP with their spouse in the past three months prior to the survey. When asked who had initiated the discussion. Almost same proportion of male and female respondent reported that both husband and wife initiated the discussion, 57.9 percent and 54.4 percent male and female respectively. However, 32.7 percent men reported that he initiated the discussion of family planning and 19.3 percent women agreed that their husband initiated the discussion. This side of the result also provides insight that gender equity in decision making on contraceptive use and rights on reproductive health is in progress. There were marginal differences found with place of residence related to initiation of spousal communication on 
FP whereas urban respondents were on higher side on reporting that discussion was initiated by both husband and wife.

Twenty-three percent of women who had achieved their desired family size also reported acceptance of permanent contraceptive measures such as female/male sterilization after completing desired family size. However, almost 70 percent of women who had achieved or surpassed their desired family size were not using any contraceptives (permanent or temporary methods). This increased the risk of unwanted pregnancy during postpartum period. The data indicated that almost 82 percent of women, who had wished to have their next child after two or more years, reported not using any contraceptives currently to delay their next child birth.

Table 7: Percentage of men and women who reported an intention to use FP in future

\begin{tabular}{lccc}
\hline \begin{tabular}{l} 
Percentage of respondents who $\begin{array}{l}\text { Want another } \\
\text { prefer to have additional children } \\
\text { in the future }(\mathrm{N}=1,655)\end{array}$ \\
\cline { 2 - 4 }
\end{tabular} & $\begin{array}{c}\text { Do not want } \\
\text { any more } \\
\text { children }\end{array}$ & Undecided \\
\cline { 2 - 4 } $\begin{array}{l}\text { Percentage of respondent } \\
\text { currently using contraceptive }\end{array}$ & 39.8 & 23.2 & 36.9 \\
\hline
\end{tabular}

$(\mathrm{N}=1521)$

Percentage of respondents who

do not use contraception who

intend to use it in the future

$(\mathrm{N}=659)$

Percentage of currently

11.8

pregnant/wife is pregnant

respondents who intend to use

contraception in the future

$(\mathrm{N}=134)$

\section{Source: IHBP survey, Chhattisgarh; 2013}

Table 7 shows that only 9.8 percent of respondents who did not desire additional children were currently using contraceptives. This showed that majority of respondents who had completed their desired family size were not using contraceptive to prevent further pregnancy. On the other hand, 18.1 percent of respondents reported using contraceptives despite desiring another child. Table 7 also showed that 14.6 percent of respondents who were not currently using contraceptives reported they would like to use contraceptives to delay their next child birth in the future. These were primarily young couples (18-29 years) and non-users. While disaggregating their preference to use for different family planning methods (temporary) found that majority of them reported male condom as most preferred method to choose (57.6 percent) in Table 8. This is followed by oral contraceptive pills (45.5 percent) and IUCD (20.5 percent). Programs need to focus on these target groups to motivate and build efficacy to initiate use of contraceptives to delay and avoid unwanted pregnancy. Only 11.8 percent women who were pregnant at the time of the survey reported an intention to accept FP after their pregnancy was completed. 
Table 8: Percentage of men and women who reported an intention to use FP in the future by type of contraceptives $(\mathrm{N}=241)$

\begin{tabular}{lc}
\hline Types of contraceptive methods & Percentage of women \\
\hline OCP & 45.5 \\
Male condom & 57.6 \\
IUCD & 20.5 \\
Injectable & 5.4 \\
Traditional method & 2.4 \\
\hline Total & $\mathbf{1 4 . 6}$ \\
\hline
\end{tabular}

Source: IHBP survey, Chhattisgarh; 2013

Table 9 shows that only 9.6 percent of non-pregnant respondents reported using any modern temporary FP method to delay their next birth (survey did not include those who were using a permanent method). This clearly showed that the prevalence of modern temporary contraceptive use was low among the study's respondent pool. Similarly respondents who had reported using contraceptives to delay their next birth and majority of them reported OCP (35.5 percent) and male condom (74.1 percent) as the preferred method. IUCD was used by 8.4 percent of respondents (women or wife of male respondent).

Table 9: Percentage of men and women (who/spouse are not pregnant during survey) who reported using FP by type to delay next child $(\mathrm{N}=159)$

\begin{tabular}{lc}
$\begin{array}{l}\text { Types of contraceptive } \\
\text { methods }\end{array}$ & $\begin{array}{c}\text { Percentage of women and men who reported currently using } \\
\text { of contraceptives to delay next birth }\end{array}$ \\
\hline
\end{tabular}

\section{OCP}

Male condom

IUCD

Traditional method

35.5

74.1

8.4

2.8

Total 9.6

Source: IHBP survey, Chhattisgarh; 2013

\section{CONCLUSIONS}

Findings from analysis of the two studies' data demonstrated multiple reasons why women do not accept contraceptives in the postpartum period. Among them, breastfeeding status and completed family size had very high influence during bivariate analysis; however the effect was not significant after controlled for other background factors. Women who were not using contraceptives during the postpartum period primarily cited breastfeeding, postpartum amenorrhea, or periodic abstinence as their reasons. Women with higher educational and economic status were more likely accept contraceptives in the postpartum period. The findings also suggested that meeting with health workers during post-partum period was positively correlated with acceptance of contraceptives immediately after child birth, though the majority of women who met with these workers during the post-partum period reported that their discussion was more focused on immunization than Family Planning. Data from study in Chhattisgarh also shows that men and women in the state are not accepted any contraceptive to prevent unwanted pregnancy even if they completed their desired family size. Intention to accept family planning is not very high.

The results also revealed that there was more focus given to acceptance of permanent methods after child birth among women who had completed their desired family size and majority of women 
accepted female sterilization to limit their family size than using long term temporary methods like IUCD, and hence focus need to be shifted towards use of long term temporary FP methods. During Reproductive \& Child Health-II, the plan was to provide FP-related counseling to women postpartum through visits by health workers, however that did not translate into action and the visits were mostly related to immunization (NFHS-3, 2006). Among young couples who have not yet completed their family size, postpartum FP should target them with greater promotion of use of spacing methods of contraceptives. In addition, introduction of Janani Surakshya Yojana (JSY) and Janani Sishu Surakshya Karyakram (JSSK) schemes under the National Health Mission may help to motivate couples to accept contraceptives during the recommended two days stay after childbirth in health facility. These schemes are proving free institutional delivery at government health facilities and in some of accredited private health facilities, with free food, blood transfusion, medicine and also transportation to health facility and back to home after child birth. Scheme like JSY has great impact on increase in institutional delivery in past few years (Paul \& Chellan, 2013). This time within the institution also provides a window of opportunity for the couple to accept long term reversible methods like IUCD after child birth to avoid the risk of unintended pregnancy during the postpartum period.

\section{REFERENCES}

AHMAD J, BHATNAGAR I., KHAN M E. (2012), Increasing access to family planning and reproductive health services through community health workers: a case study of a dual cadre model in India: The Population Council, Washington, DC.

BORDA M., WINFREY B. (2010). Postpartum Fertility and Contraception: An Analysis of Findings from 17 Countries. ACCESS-FP: Baltimore, Maryland.

Cleland J, Bernstein S., Ezeh A., Faundes A., Glasier A., Innis J., (2006). Family Planning: The Unfinished Agenda. The Lancet 368 (9549), 110-1827.

Ekpenyoung, Chris E, Nyebuk E Daniel, Anthony Fidelis Uwah, Ette Okon Ettebong and John O. Ibu. 2013. Lactational Amenorrhoea Method of Contraception and in-dpeth Study of Awareness Knowledge and Practice by Breastfeeding Mothers with Unintended Pregnancies. International Journal of Medicine and Medical Sciences 5 (1) : 6-13.

Faculty of Family Planning and Reproductive Health. 2004. FFPRHC Guidance: Contraceptive Choices for Breast Feeding Women. Journal of family planning and Reproductive Health Care 30 (3): 181-189.

Gangopadhyay, Bhaswati; Das, D.N.1997. Quality of Family Planning Services in India: The Users Perspective. The Journal of Family Welfare. 43(3).p.5-12.

IIPS and Macro International, 2007. National Family Health Survey-3. India Vol. 1. Mumbai: IIPS.

Kish, Leslie. 1949. A Procedure for Objective Respondent Selection within the Household. Journal of the American Statistical Association, 44 (247): 380-387.

Kishore Surekha, B. S. Garg, P. R. Deshmukh, Pradeep Agarwal. 2010. Role of Lactation in Family Planning. Indian Journal of Community Health 21 (2) : 4-7.

Kunwar, Shipra, Mohammad M. A. Faridi, Shivani Singh, Fatima Zahra, Zeashan Alizaidi .2010. Pattern and Determinant of Breastfeeding and Contraceptive Practice Among Mothers Within Six Months Postpartum. Bioscience Trends 4 (4) : 186-189.

Mahmood, Syed Esam, Anurag Srivastava, Ved Prakash Shrotriya, Iram Shaifali, Payal Mishra. 2011. Postpartum Contraceptive Use in Rural Bareilly. Indian journal of Community Health 23 (2) : 56-57.

Mondal Subrato Kumar, Ajay K Singh, Lopamudra Paul, Geeta Nanda, A V Surya, Trilok Sisodiya, Sanjana Arora. 2014. Reach \& Recall of Family Planning Campaign in Chhattisgarh. New Delhi : IHBP.

Mosley, W. H., T. Osteria and S. 1. Huffman. 1977. Interaction of Contraception and Breast Feeding in Developing countries. Biosocial Science Suppl 4 : 93-111.

Paul, Lopamudra and Ramesh Chellan. 2013. Impact of Janani Sishu suraksha Yojana on Institutional Delivery in Empowered Action group States, India. South East Asia Journal of Public Health 3 (2) : 4-18. 
Rangarajan Anu, Evan Borkum, Swetha Sridharan,Dana Rotz, Mercy Manoranjini, Seth Morgan, Lalit Dandona, Rakhi Dandona, Priyanka Chaman, G. Anil Kumar. 2013. Baseline Findings from Ananya Evaluation. New Delhi: Bill \& Melinda Gates Foundation, India (unpublished).

Ross J. A. and W. L Winfrey. 2001. Contraceptive Use, Intent to Use and Unmet Needs During the Extended Postpartum Period. International Family Planning Perspectives 27: 20-27.

Sabu S. Padmadas, Inge Hutter and Frans Willekens. 2004. Compression of Women's Reproductive Spans in Andhra Pradesh, India. International Family Planning Perspectives 30 (1): 12-19.

Shukla, Manju, Sabuhi Qureshi \& Chandrawati. 2012. Post-placental Intrauterine Device Insertion- a Five Year Experience at a Tertiary Care Centre in North India. Indian Journal of Medical Research 136: 432-435.

Spolanki Harsa M, Chavan Mansi K Chavan, Velhal Gajanan D, Mehul T Paemar. 2013. A Comparative Study Between Met and Unmet Need Groups of Contraception in Rural Areas of MAHARASHTRA, India. Global Journal of Medicine and Public Health (2) : 1-7. 
Table 4: Acceptance of contraceptive methods by background characteristics among women with children less than one year of age, (NFHS-3), 2005-06

\begin{tabular}{|c|c|c|c|c|}
\hline \multirow[t]{2}{*}{ Background characteristics } & \multirow{2}{*}{$\begin{array}{l}\text { Percentage of } \\
\text { women } \\
\text { (unadjusted) }\end{array}$} & \multirow{2}{*}{$\begin{array}{l}\text { Odds ratio } \\
\text { adjusted }\end{array}$} & \multicolumn{2}{|c|}{ CI $(95 \%)$} \\
\hline & & & lower & upper \\
\hline \multicolumn{5}{|l|}{ Place of residence } \\
\hline Rural (rc) & 22.1 & 1.000 & & \\
\hline Urban & 35.9 & 1.053 & 0.961 & 0.223 \\
\hline \multicolumn{5}{|l|}{ Religion } \\
\hline Hindu (rc) & 25.8 & 1.000 & & \\
\hline Muslim & 22.5 & 0.841 & 0.605 & 0.956 \\
\hline Christian \& others & 30.7 & 1.123 & 0.867 & 1.335 \\
\hline \multicolumn{5}{|l|}{ Ethnicity } \\
\hline Non SC/ST/OBC (rc) & 30.2 & 1.000 & & \\
\hline Scheduled caste & 23.5 & 1.034 & 0.867 & 1.158 \\
\hline Scheduled Tribe & 19.4 & 1.035 & 0.832 & 1.231 \\
\hline Other backward castes & 24.6 & 0.986 & 0.987 & 1.110 \\
\hline \multicolumn{5}{|l|}{ Age } \\
\hline $15-19(\mathrm{rc})$ & 15.0 & 1.000 & & \\
\hline $20-24$ & 25.9 & 1.365 & 1.112 & 1.568 \\
\hline $25-29$ & 30.4 & 1.472 & 1.015 & 1.843 \\
\hline $30-34$ & 28.8 & 1.393 & 1.248 & 1.521 \\
\hline $35-39$ & 21.6 & 1.061 & 0.984 & 1.129 \\
\hline 40 and above & 25.3 & 1.120 & 1.042 & 1.217 \\
\hline \multicolumn{5}{|l|}{ Wealth Index } \\
\hline Poorer (rc) & 15.0 & 1.000 & & \\
\hline Poor & 19.7 & 0.831 & 0.784 & 1.686 \\
\hline Middle & 24.5 & 0.975 & 0.896 & 1.034 \\
\hline Richer & 32.5 & $* * 1.232$ & 1.139 & 2.001 \\
\hline Richest & 44.9 & $* * 1.646$ & 1.408 & 1.840 \\
\hline \multicolumn{5}{|l|}{ Educational level } \\
\hline Illiterate (rc) & 17.4 & 1.000 & & \\
\hline Primary & 23.8 & 0.893 & 0.752 & 1.273 \\
\hline Secondary & 33.2 & 1.101 & 0.986 & 1.527 \\
\hline Higher & 49.5 & $* * 1.479$ & 1.210 & 1.759 \\
\hline \multicolumn{5}{|l|}{$\begin{array}{l}\text { Interaction with } \mathrm{HW} / \mathrm{CW} \text { in past } \\
\text { three month }\end{array}$} \\
\hline No (rc) & 25.0 & 1.000 & & \\
\hline Yes & 26.1 & $* 1.076$ & 0.987 & 1.128 \\
\hline \multicolumn{5}{|l|}{$\begin{array}{l}\text { Institutional delivery (only last } \\
\text { delivery) }\end{array}$} \\
\hline No (rc) & 14.4 & 1.000 & & \\
\hline Yes & 34.0 & $* * 1.149$ & 1.020 & 1.328 \\
\hline \multicolumn{5}{|l|}{ Completed family size } \\
\hline Undecided (rc) & 13.5 & 1.000 & & \\
\hline $\begin{array}{l}\text { Having number of living children as } \\
\text { desired or more }\end{array}$ & 30.1 & $* * 1.691$ & 1.608 & 2.494 \\
\hline $\begin{array}{l}\text { Having number of living child lower } \\
\text { than desired }\end{array}$ & 24.2 & 0.964 & 0.802 & 1.059 \\
\hline \multicolumn{5}{|l|}{ Currently breast feeding } \\
\hline Yes (rc) & 27.3 & 1.000 & & \\
\hline No & 25.3 & 0.538 & 0.421 & 0.846 \\
\hline Total number of women & & 10,755 & & \\
\hline
\end{tabular}

Source: Computed from NFHS-3 data files 